\title{
Nematic Phase of Plate-like Semicrystalline Block Copolymer Single Crystals in Solution Studied by SAXS
}

\author{
Enyi Chi ${ }^{\mathrm{a}, \mathrm{b}}$, Haiying Huang ${ }^{\mathrm{a}, \mathrm{b}^{*}}$, Fajun Zhang ${ }^{\mathrm{c} *}$, Tianbai He $\mathrm{H}^{\mathrm{a}, \mathrm{b}}$ \\ ${ }^{\mathrm{a}}$ State Key Laboratory of Polymer Physics and Chemistry, Changchun Institute of Applied \\ Chemistry, Chinese Academy of Sciences, Changchun 130022, P. R. China. \\ bUniversity of Chinese Academy of Sciences, Beijing 100049, P. R. China \\ Institut für Angewandte Physik, Universität Tübingen, Auf der Morgenstelle 10, 72076 \\ Tübingen, Germany. \\ * To whom correspondence should be addressed. \\ E-mail: fajun.zhang@uni-tuebingen.de (FJ. Zhang) \\ hyhuang@ciac.ac.cn (HY. Huang)
}



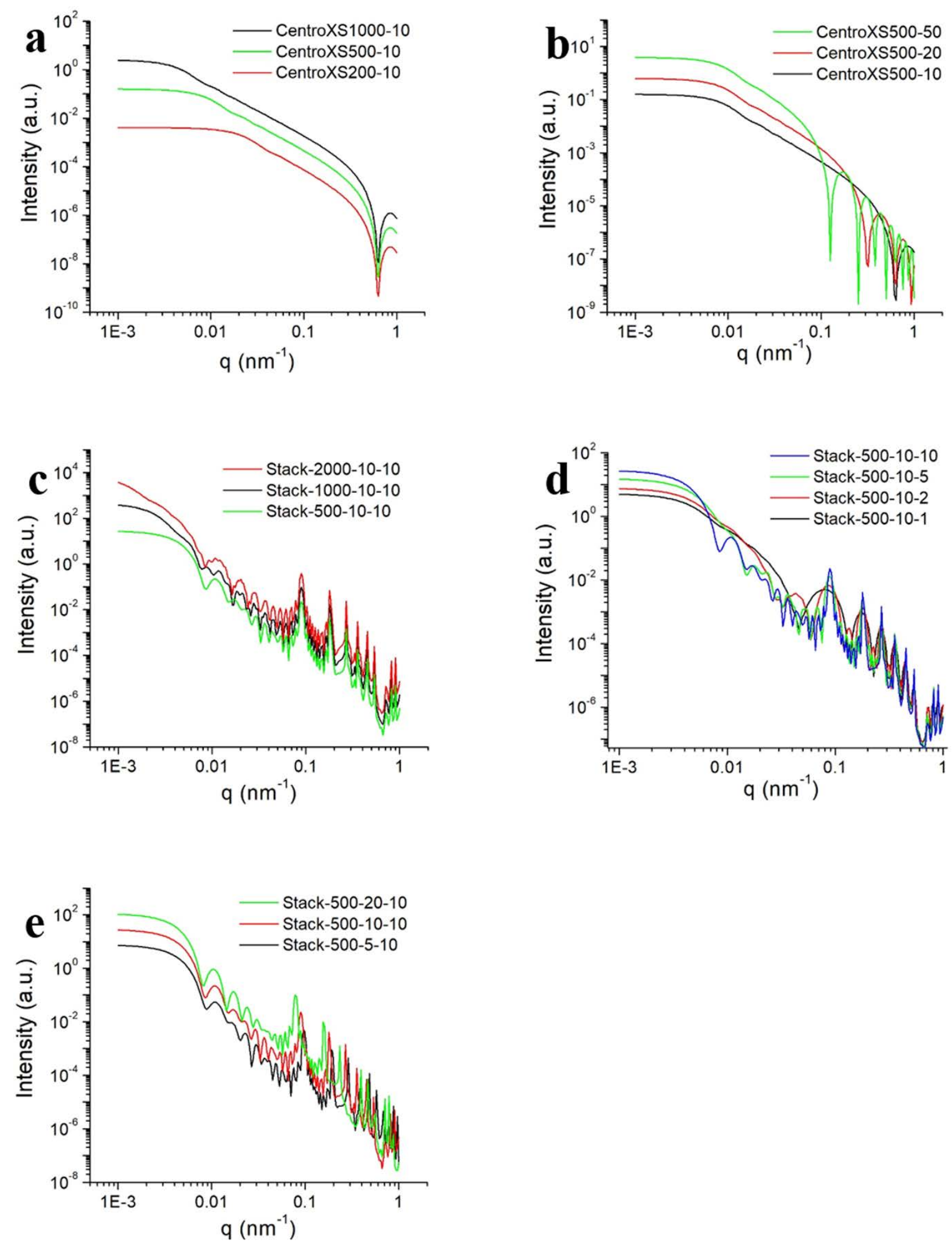

Figure S1. Simulated scattering profile using the disc and stacked disc cluster model. (a) Single disc with a thickness of $10 \mathrm{~nm}$ and varying diameters of 200, 500 and $1000 \mathrm{~nm}$; (b) Single disc with a fixed diameter of $500 \mathrm{~nm}$ and varying thickness of 10, 20 and $50 \mathrm{~nm}$; (c) Stacked discs with different diameters but fixed thickness (10nm) and number of disc (10); (d) 
Stacked discs with fixed diameter $(500 \mathrm{~nm})$ and thickness $(10 \mathrm{~nm})$ but varying the number of disc (1, 2, 5 and 10); (e) Stacked discs with fixed diameter (500nm) and number of discs (10) but varying the thickness (5, 10 and $20 \mathrm{~nm})$.

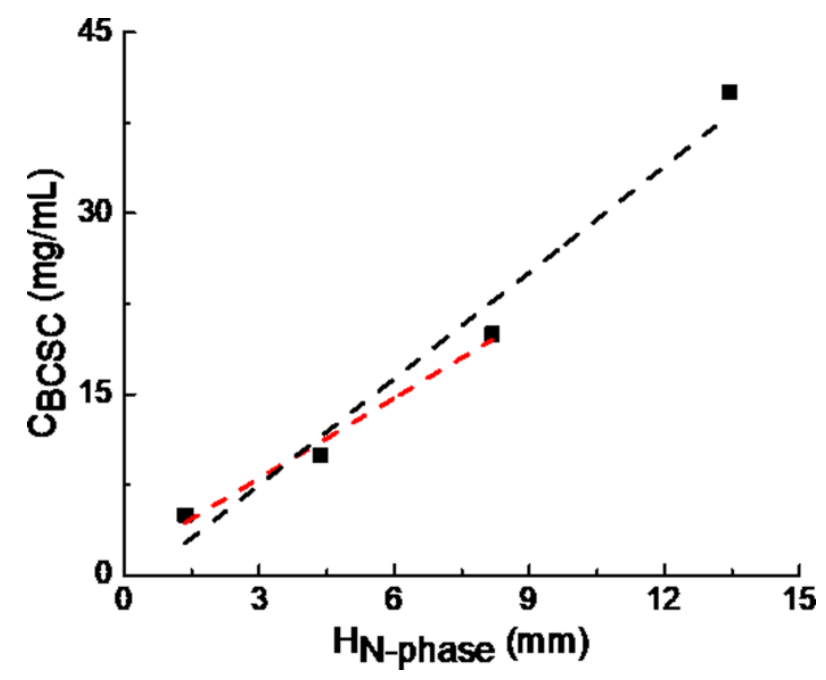

Figure S2. Estimation of I-N boarder based on the height of the N phase for BCSC1000. We measure the heights of $\mathrm{N}$ phases of different concentration samples and give the relationship of concentration of suspensions and height of $\mathrm{N}$ phase. A linear relationship (black dash line) with all four data points indicates that the density of dense phase is the same with different initial concentrations. However, as the $40 \mathrm{mg} / \mathrm{mL}$ suspension forms a large transient zone, the height of this sample deviates from the linear regression. Using only the first three data, the linear regression (red dash line) gives an intercept of $1.4 \mathrm{mg} / \mathrm{mL}$ (corresponding to a volume fraction of $0.12 \%$ ) which corresponds to the I-N boarder.

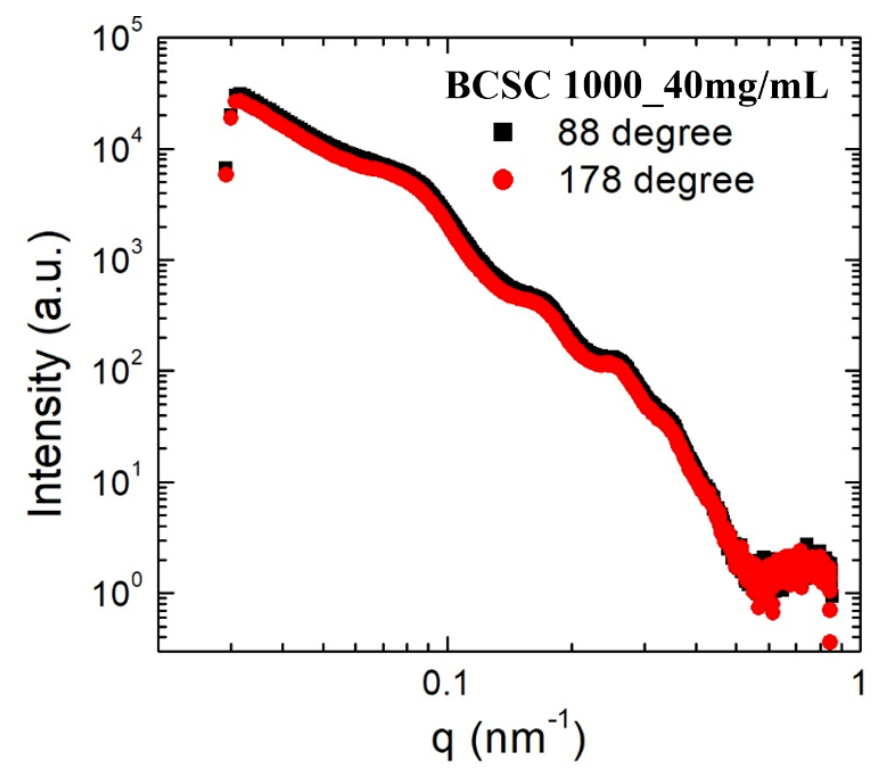


Figure S3. SAXS profiles along the vertical and horizontal direction from anisotropic 2D SAXS patterns for BCSC1000 with $40 \mathrm{mg} / \mathrm{mL}$.
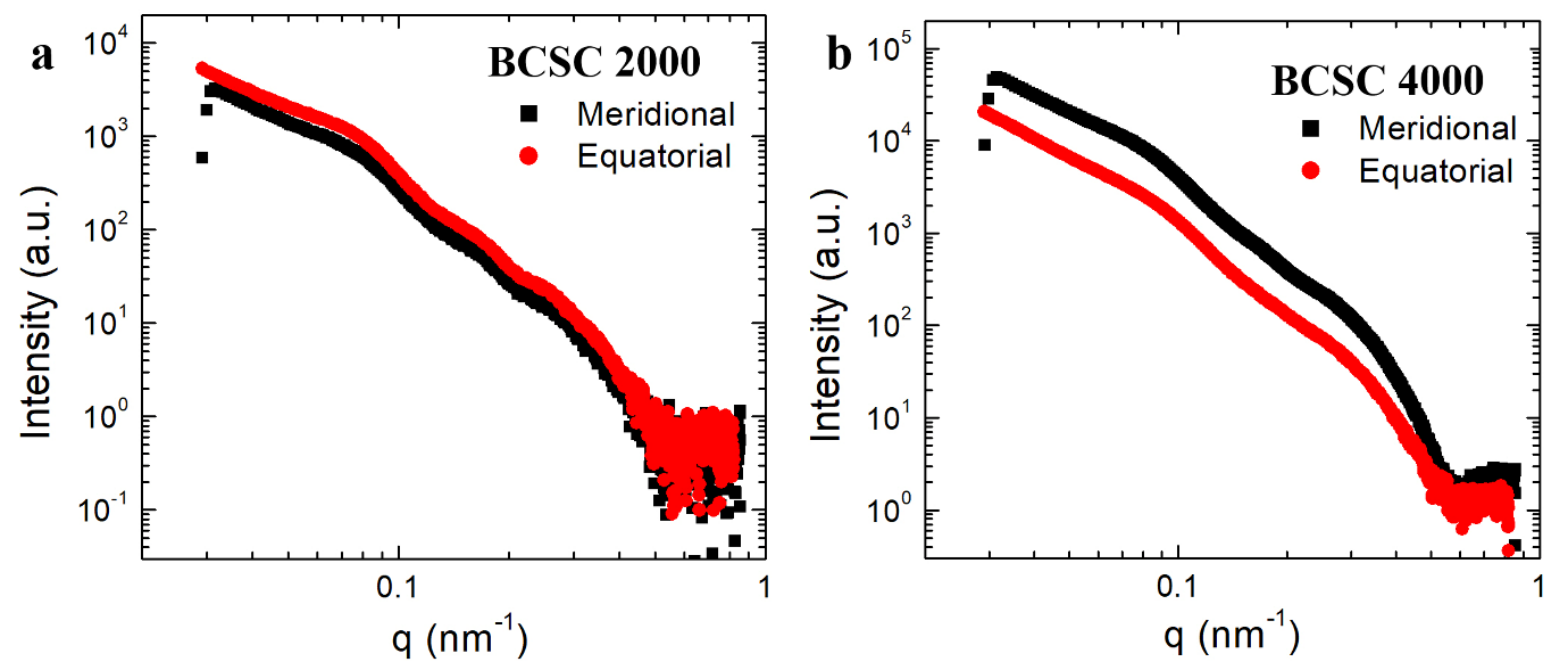

Figure S4. SAXS profiles along the vertical and horizontal direction from anisotropic 2D SAXS patterns for BCSC2000 (a) and BCSC4000 (b), respectively. 